\title{
Clinical and radiographic sequelae to primary teeth affected by dental trauma: a 9-year retrospective study
}

Vanessa Polina Pereira COSTA ${ }^{(a)}$ Marilia Leão GOETTEMS (b) Elaine Zanchin BALDISSERA ${ }^{(c)}$ Andréa Dâmaso BERTOLDI(d) Dione Dias TORRIANI(e) (in memoriam)

(a) Universidade Federal de Pelotas, School of Dentistry, Post-Graduate Program, Pelotas, RS, Brazil.

(b) Universidade Federal de Pelotas, School of Dentistry, Department of Social and Preventive Dentistry, Pelotas, Brazil.

(c) Universidade Federal de Pelotas, School of Dentistry, Department of Clinic, Pelotas, Brazil.

(d) Universidade Federal de Pelotas, School of Dentistry, Epidemiology Post-Graduate Program, Pelotas, RS, Brazil.

(e) Universidade Federal de Pelotas, School of Dentistry, Department of Social and Preventive Dentistry, Pelotas, Brazil.

Declaration of Interests: The authors certify that they have no commercial or associative interest that represents a conflict of interest in connection with the manuscript.

\section{Corresponding Author:}

Vanessa Polina Pereira Costa

E-mail: polinatur@yahoo.com.br

DOI: 10.1590/1807-3107BOR-2016.vol30.0089

Submitted: May 21, 2015

Accepted for publication: Mar 23, 2016

Last revision: May 15, 2016
Abstract: This retrospective study aimed at determining the predicted risks of clinical and radiographic complications in primary teeth following traumatic dental injuries, according to injury type, severity and child's age. Data were collected from records of children treated at a Dental Trauma Center in Brazil for nine years. Records of 576 children were included; clinical sequelae were assessed in 774 teeth, and radiographic sequelae, in 566 teeth. A total of 408 teeth (52.7\%) had clinical sequelae and 185 teeth (32.7\%), radiographic sequelae. The type of injury with the highest number of clinical sequelae was the crown-root fracture $(86.4 \%)$. Clinical sequelae increased with injury severity $(p<0.001)$, whereas radiographic sequelae did not $(0.236)$. The predicted risk of color change was $29.0 \%$ (95\% CI 19-41) for teeth with enamel fracture, and $26.0 \%$ (95\%CI 14-40) for teeth with enamel dentin fracture as well as enamel dentin pulp fracture. Risk of periapical radiolucency was higher for teeth with enameldentinpulp fracture $(61.1 \% 95 \% \mathrm{CI} 35-82)$ and those with subluxation (15.8\% 95\%CI 10-22). Risk of premature loss was $27.3 \%$ (95\%CI 13-45) for teeth with extrusive luxation, and 10.2\% (95\%CI 5-17) for those with intrusive luxation. The assessment of predicted risks of sequelae showed that teeth with hard tissue trauma tended to present color change, periapical radiolucency and premature loss, whereas teeth with supporting tissue trauma showed color change, abnormal position, premature loss and periapical radiolucency as the most common sequelae. Knowledge about the predicted risks of complications may help clinicians establish appropriate treatment plans.

Keywords: Injury Severity Score; Tooth, Deciduous; Tooth Injuries.

\section{Introduction}

The maintenance of the primary dentition is important to ensure aesthetics and function, and also to guide the eruption of permanent teeth. Traumatic dental injuries may affect this balance, and are therefore recognized as an important oral health problem. ${ }^{1}$ The study of dental trauma in the primary dentition has gained importance, owing to its high prevalence found in epidemiological studies, ranging from $9 \%$ to $62 \%, 2,3,4$ and to its potential to generate sequelae in traumatized primary teeth, varying from a color change to the premature loss of a tooth. $5,6,7$ Knowledge of post-injury sequelae allows establishing the best way to treat and prevent possible complications. ${ }^{8}$ 
The severity of the traumatic injuries is an important predictor of traumatized tooth prognosis. Moreover, treatment becomes more complex and a specialized staff for diagnosis and follow-up examinations may be required, depending on the degree of severity. ${ }^{9}$ The more severe the injury, the more serious the consequences arising from it, including impairment of formation and development of the permanent teeth, and more extensive and costly treatments.

Therefore, the possible consequences of the different types of injury should be known to predict and prevent possible abnormalities. ${ }^{10}$ A previous study showed that $24.8 \%$ of injured teeth developed pulp necrosis and $35.9 \%$, pulp obliteration ${ }^{6}$. Knowledge about the risk of developing complications may help clinicians determine the prognosis of traumatized primary teeth. An assessment of the predicted risks of complications for permanent teeth is available from the IADT. ${ }^{11}$ However, to our knowledge, information on the predicted risks of complications according to trauma type is not available for primary teeth.

This retrospective study aimed at determining the predicted risks of clinical and radiographic complications in primary teeth, according to trauma type and injury severity, in children aged between 8 and 89 months, treated at a specialized center.

\section{Methodology}

\section{Study settings and design}

This longitudinal retrospective study collected data from the dental records and radiographs of patients with Traumatic Dental Injuries (TDI) who were treated by the Center for the Study and Treatment of Dental Trauma in the Primary Dentition (hereafter, NETRAD, the acronym in Portuguese), between May 2002 and July 2011. This service is connected to the Pediatric Dentistry Clinic of the Federal University of Pelotas, Brazil. The clinic provides access, treatment, and follow-up assistance for TDIs in the primary dentition. The protocol of attendance is based on the recommendations of the International Association of Dental Traumatology (IADT) Guidelines. ${ }^{12}$ All children receiving this service are accompanied until the eruption of their permanent teeth.

\section{Data collection}

According to NETRAD's protocol, parents or responsible caregivers initially answer questions in an interview regarding the child's medical history and dental trauma history. Then, a clinical and radiographic examination is conducted, according to the TDI type. ${ }^{12,13}$

One previously trained researcher (VPPC) collected the clinical information from the NETRAD records, including the child's age (in months), the type of injury and the presence of clinical sequelae of patients having completed at least two follow-ups. The researcher was also trained and calibrated to conduct radiographic analyses to determine the presence of radiographic sequelae. Radiographic evaluations were performed using an X-ray viewing box and a magnifying glass. The radiographs of all the appointments of the patients were assessed. The inclusion criteria were: records with complete documentation about the TDI that affected hard tissue or supporting tissue, with minimum follow-up of two dental appointments. Any incorrectly filled out dental records, poor-quality radiographic records, children with TDI only in soft tissues, diagnoses other than TDI, and children with less than two dental visits were excluded. When the same tooth had more than one dental trauma during follow-up, only the first injury was considered.

Clinical and radiographic sequelae were classified according to the following criteria. 5,6,14 The clinical sequelae were: 1 = color change (including yellow and grey discoloration); 2 = presence of fistula and/or swelling; 3 = abnormal position; 4 = premature loss of the tooth. The radiographic sequelae were: 1 = pathological root resorption; $2=$ accelerated root resorption (as compared with the homologous non-injured teeth); 3 = pulp obliteration; $4=$ periapical radiolucency, taking into account that no alterations were observed in the first examination. When more than one possible sequela was present in one tooth, all of the sequelae detected were recorded.

The type of TDI was classified according to Andreasen et al. ${ }^{13}$ criteria. Injury severity was classified as mild, moderate and severe, according to Oikarinen and Kassila. ${ }^{9}$ Mild injuries included subluxation, concussion, enamel fracture, and enamel-dentin fracture. Moderate injuries included lateral luxation, 
extrusion and enamel-dentin-pulp fracture. Severe injuries included avulsion, intrusion, crown-root fracture, and root fracture.

\section{Calibration procedure}

Intraexaminer variability was tested based on the kappa coefficient, using 80 periapical radiographs depicting different conditions. The results of the examiner were compared with a gold standard, in this case, a PhD in Radiology. The kappa value was 0.91 , thus showing excellent agreement.

\section{Data analysis}

The data were entered twice in an EpiInfo 6.04 database, and checked for consistency. Statistical analysis was performed using Stata 12.0 (Stata Corp. LP, College Station, USA). Data analysis included descriptive statistics, and the chi-squared and Fisher's exact test were used to determine associations of sequela versus injury severity. The level of significance was set at $5 \%$.

\section{Ethical considerations}

The study was approved by the local Human Research Ethics Committee (Protocol 187/2011). The parents or caregivers were asked to sign an informed consent agreement prior to initiating the clinical activities. Children received full dental treatment.

\section{Results}

Of the 707 records of children who sought assistance during the period studied, 131 records were excluded. Reasons for exclusion are showed in Figure 1. A total of 576 records from children with TDIs in the primary dentition were analyzed, including 342 boys (59.4\%) and 234 girls (40.6\%), aged between 8 and 89 months (mean age $=41.1$ months). The records analyzed resulted in 898 injured teeth that were assessed for the presence of sequelae. Superior central incisors $(77.8 \%)$ were the most affected teeth. Of the total, 774 teeth were assessed for clinical sequelae in 454 children, and 566 teeth, for radiographic sequelae in 339 children. Moreover, 124 teeth in 122 children were excluded due to lack of information on the clinical records or failure to attend the dental appointments, and 332 teeth in 237 children were excluded due to radiographs with technical errors or failure to seek radiograph follow-up.

Table 1 shows the frequency of clinical and radiographic sequelae according to type of injury, severity of the trauma and age of the child. A total of $52.7 \%$ (408) of the teeth presented clinical sequelae, whereas radiographic sequelae were detected in

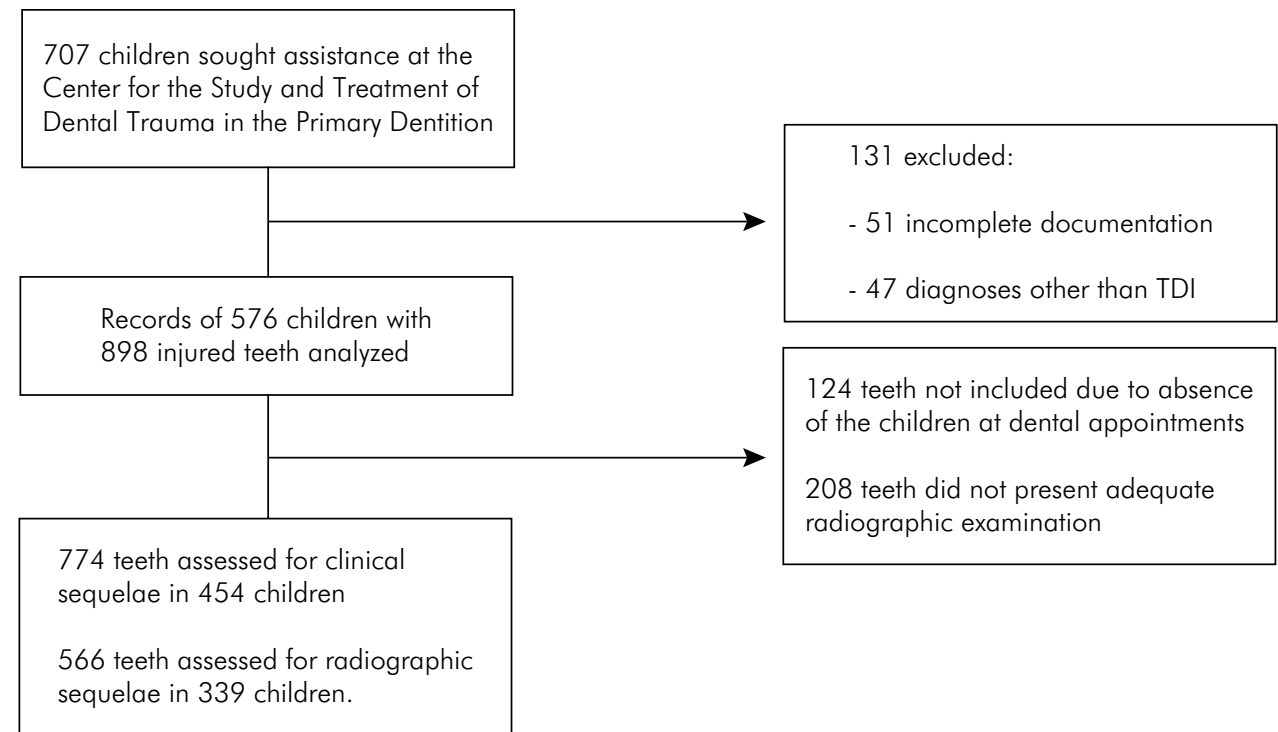

Figure 1. Flowchart of the study conducted in the Center for the Study and Treatment of Dental Trauma in the Primary Dentition (NETRAD). 
$32.7 \%$ (185). The presence of both clinical and radiographic sequelae occurred in 126 teeth. A higher frequency of clinical sequelae was detected in teeth with crown-root fracture (86.4\%) and avulsion (82.1\%). Regarding radiographic sequelae, alterations were present in $66.7 \%$ of the teeth with root fracture and in $61.1 \%$ of the teeth with enamel-dentin-pulp fracture. Of the 145 teeth with avulsion, 26 (17.9\%) did not represent clinical sequelae, since the loss was compatible with the child's age, and 7 teeth were replanted, 5 of which had radiographic sequelae (71.4\%): one had accelerated resorption and the other 4, periapical radiolucency. Considering the child's age at the time of injury, children at 37-42 months had a higher frequency of clinical sequelae (62.4\%), and children 43-60 months had a higher frequency

Table 1. Presence of clinical and radiographic sequelae according to type of injury, child's age at the time of TDI, and injury severity. (NETRAD). Pelotas, Brazil, 2015.

\begin{tabular}{|c|c|c|c|c|c|c|}
\hline & \multicolumn{2}{|c|}{ Clinical Sequelae } & \multirow{3}{*}{$p^{*}$} & \multicolumn{2}{|c|}{ Radiographic Sequelae } & \multirow{3}{*}{$p^{*}$} \\
\hline & Yes & No & & Yes & No & \\
\hline & n (\%) & n (\%) & & n (\%) & n (\%) & \\
\hline \multicolumn{7}{|l|}{ TDI } \\
\hline FE & $27(37.0)$ & $46(63.0)$ & \multirow{11}{*}{$\leq 0.001$} & $19(26.8)$ & $52(73.2)$ & \multirow{11}{*}{0.011} \\
\hline FED & $21(42.0)$ & $29(58.0)$ & & $22(44.0)$ & $28(56.0)$ & \\
\hline FEDP & $15(65.2)$ & $8(34.8)$ & & $11(61.1)$ & $7(38.9)$ & \\
\hline $\mathrm{FCR}$ & $19(86.4)$ & $3(13.6)$ & & $3(33.3)$ & $6(66.7)$ & \\
\hline $\mathrm{FR}$ & $3(75.0)$ & $1(25.0)$ & & $2(66.7)$ & $1(33.3)$ & \\
\hline Concussion & $10(17.2)$ & $48(82.8)$ & & $11(19.0)$ & $47(81.0)$ & \\
\hline Subluxation & $69(43.1)$ & $91(56.9)$ & & $49(31.0)$ & $109(69.0)$ & \\
\hline Lateral Lux. & $54(55.0)$ & $44(45.0)$ & & 27 (33.3) & $54(66.7)$ & \\
\hline Intrusive Lux. & $51(47.2)$ & $57(52.8)$ & & $30(34.5)$ & $57(65.5)$ & \\
\hline Extrusive Lux. & $20(60.6)$ & $13(39.4)$ & & $6(25.0)$ & $18(75.0)$ & \\
\hline Avulsion & $119(82.1)$ & $26(17.9)$ & & $5(71.4)$ & $2(28.6)$ & \\
\hline \multicolumn{6}{|l|}{ Age-TDI } & \multirow{7}{*}{0.031} \\
\hline 0-12 months & $9(34.6)$ & $17(65.4)$ & & $2(9.1)$ & $20(90.9)$ & \\
\hline $\operatorname{dez} / 24$ & $60(48.4)$ & $64(51.6)$ & & $33(32.0)$ & $70(67.9)$ & \\
\hline $25-36$ & $105(58.7)$ & 74 (41.3) & $\leq 0.001$ & $56(37.8)$ & 92 (70.2) & \\
\hline $37-42$ & $123(62.4)$ & 74 (37.6) & & $42(29.8)$ & 99 (70.2) & \\
\hline $43-60$ & $68(54.8)$ & $56(45.2)$ & & $34(41.5)$ & $48(58.5)$ & \\
\hline$>60$ & 43 (34.7) & 81 (65.3) & & $18(25.7)$ & $52(74.3)$ & \\
\hline \multicolumn{6}{|l|}{ Gender } & \multirow{3}{*}{0.44} \\
\hline Male & $245(53.6)$ & $212(46.4)$ & 0.55 & 116 (33.9) & $226(66.1)$ & \\
\hline Female & $163(51.4)$ & $154(48.6)$ & & $69(30.8)$ & $155(69.2)$ & \\
\hline \multicolumn{6}{|l|}{ Severity } & \multirow{5}{*}{0.236} \\
\hline Mild & 127 (37.3) & $214(62.7)$ & & 101 (30.0) & $236(70.0)$ & \\
\hline Moderate & 89 (57.8) & $65(42.2)$ & $\leq 0.001$ & $44(35.8)$ & $79(64.2)$ & \\
\hline Severe & $192(68.8)$ & 87 (31.2) & & $40(37.7)$ & $66(62.3)$ & \\
\hline Total & $408(52.7)$ & $366(47.3)$ & & 185 (32.7) & 381 (67.3) & \\
\hline
\end{tabular}

${ }^{*}$ Chi: squared test; FE: enamel fracture; FED: enamel-dentin fracture; FEDP: enamel-dentin-pulp fracture; FCR: crown-root fracture; FR: root fracture. 
of radiographic sequelae (41.5\%). The presence of clinical sequelae increased with injury severity $(\mathrm{p}<$ 0.001). However, radiographic sequelae showed no association with degree of severity $(0.236)$.

Table 2 shows the predicted risks of complications after hard tissue injuries. The risk of presenting color change was $29.0 \%$ (95\% CI 19-41) for teeth with enamel fracture, and $26.0 \%$ for teeth with enamel-dentin fracture (95\% CI 14-40) as well as enamel-dentin-pulp fracture (95\%CI 10-48). Teeth diagnosed with crown-root fracture had a risk of
$81.8 \%$ (95\%CI 59-94) of premature loss. Most teeth with complicated crown fractures developed periapical radiolucency (61.1\%), requiring endodontic treatment.

Table 3 shows the predicted risks of complications after support tissue injuries. Risk of premature tooth loss was 27.3\% (95\%CI 13-45) for teeth with extrusive luxation, a result higher than the $10.2 \%$ risk of loss as a consequence of intrusive luxation (95\%CI5-17) and the $9.2 \%$ risk of lateral luxation ( $95 \% \mathrm{CI} 4-16)$. Accelerated root resorption was perceived in $10.3 \%$ (95\%CI3-21) of the teeth with concussion, and periapical radiolucency,

Table 2. Predicted risks of sequelae, according to type of hard tissue trauma. (NETRAD). Pelotas, Brazil, 2015.

\begin{tabular}{lccccc}
\hline \multirow{2}{*}{ Clinical sequelae } & $\mathrm{FE}(\mathrm{n}=73)$ & $\mathrm{FED}(\mathrm{n}=50)$ & $\mathrm{FEDP}(\mathrm{n}=23)$ & $\mathrm{FCR}(\mathrm{n}=22)$ & $\mathrm{FR}(\mathrm{n}=4)$ \\
\cline { 2 - 6 } & $\mathrm{N}(\% ; 95 \% \mathrm{Cl})$ & $\mathrm{N}(\% ; 95 \% \mathrm{Cl})$ & $\mathrm{N}(\% ; 95 \% \mathrm{Cl})$ & $\mathrm{N}(\% ; 95 \% \mathrm{Cl})$ & $\mathrm{N}(\% ; 95 \% \mathrm{Cl})$ \\
\hline Color change & $21(29.0 ; 19-41)$ & $13(26.0 ; 14-40)$ & $6(26.0 ; 10-48)$ & $1(4.5 ; 0.1-22)$ & $2(50.0 ; 1.2-98)$ \\
Fistula/swelling & $2(2.7 ; 0-9)$ & $5(10.0 ; 3-21)$ & $2(8.7 ; 1-28)$ & $0(-)$ & $0(-)$ \\
Abnormal position & $3(4.1 ; 0.8-11)$ & $0(-)$ & $1(4.3 ; 0.1-21)$ & $0(-)$ & $1(25.0 ; 0.6-80)$ \\
Premature loss & $1(1.4 ; 0-7)$ & $0(-)$ & $6(26.1 ; 10-48)$ & $18(81.8 ; 59-94)$ & $0(-)$ \\
\hline Radiographic sequelae & $\mathrm{FE}(\mathrm{n}=71)$ & $\mathrm{FED}(\mathrm{n}=50)$ & $\mathrm{FEDP}(\mathrm{n}=18)$ & $\mathrm{FCR}(\mathrm{n}=9)$ & $\mathrm{FR}(\mathrm{n}=3)$ \\
\cline { 2 - 6 } & $\mathrm{n}(\% ; 95 \% \mathrm{Cl})$ & $\mathrm{n}(\% ; 95 \% \mathrm{Cl})$ & $\mathrm{n}(\% ; 95 \% \mathrm{Cl})$ & $\mathrm{n}(\% ; 95 \% \mathrm{Cl})$ & $\mathrm{n}(\% ; 95 \% \mathrm{Cl})$ \\
\hline Pathological root resorption & - & $3(6.0 ; 1.2-16)$ & $0(-)$ & $0(-)$ & $0(-)$ \\
Accelerated root resorption & $2(2.8)(0-0.84)$ & $0(-)$ & $0(-)$ & $0(-)$ & $1(33.3 ; 0.8-90)$ \\
Pulp obliteration & $6(8.4 ; 0.3-9)$ & $0(-)$ & $0(-)$ & $0(-)$ & $0(-)$ \\
Periapical radiolucency & $11(15.5 ; 7-26)$ & $19(38.0 ; 24-52)$ & $11(61.1 ; 35-82)$ & $3(33.3 ; 7-70)$ & $1(33.3 ; 08-90)$ \\
\hline
\end{tabular}

$\mathrm{N}=$ number of diagnosed events; $\%=$ estimated risk; $95 \% \mathrm{Cl}=95 \%$ confidence interval; FE: enamel fracture; FED: enamel-dentin fracture; FEDP: enamel-dentin-pulp fracture; FCR: crown-root fracture; FR: root fracture.

Table 3. Predicted risks of sequelae, according to type of supporting tissue trauma. (NETRAD). Pelotas, Brazil, 2015. n(\%;95\%CI).

\begin{tabular}{|c|c|c|c|c|c|c|}
\hline Variable & Concussion & Subluxation & Lateral Luxation & Intrusive Luxation & $\begin{array}{l}\text { Extrusive } \\
\text { Luxation }\end{array}$ & Avulsion \\
\hline Clinical Sequelae & 58 & 160 & 98 & 108 & 33 & 145 \\
\hline Color Change & $9(15.5 ; 7-27)$ & $55(34.4 ; 27-42)$ & $23(23.5 ; 15-33)$ & $17(15.7 ; 9-24)$ & $8(24.2 ; 11-42)$ & $2(1.4 ; 0.1-4)$ \\
\hline Fistula/Swelling & $0(-)$ & $4(2.5 ; 0.6-6.2)$ & $2(2.0 ; 0.2-71)$ & $5(4.6 ; 1-10)$ & $0(-)$ & $0(-)$ \\
\hline Abnormal position & $1(1.7 ; 0-9)$ & $6(3.7 ; 1.3-7.9)$ & $19(19.4 ; 12-28)$ & $18(16.7 ; 10-25)$ & $2(6.1 ; 0.7-20)$ & $2(1.4 ; 0.1-4)$ \\
\hline Premature Loss & $0(-)$ & $1(0.6 ; 0-3.4)$ & $9(9.2 ; 4-16)$ & $11(10.2 ; 5-17)$ & $9(27.3 ; 13-45)$ & $115(79.3 ; 71-85)$ \\
\hline Radiographic sequelae & 58 & 158 & 81 & 87 & 24 & 7 \\
\hline Pathological root resorption & $0(-)$ & $6(3.8 ; 14-80)$ & $2(2.5 ; 0.3-8)$ & $2(2.3 ; 0.2-8)$ & $0(-)$ & $0(-)$ \\
\hline Accelerated root resorption & $6(10.3 ; 3-21)$ & $3(1.9 ; 0.3-5.4)$ & $6(7.4 ; 2-15)$ & $3(3.4 ; 0.7-9)$ & $3(12.5 ; 2-32)$ & $1(14.3 ; 0.3-57)$ \\
\hline Pulp obliteration & $5(8.6 ; 2-18)$ & $15(9.5 ; 5.4-15.1)$ & $10(12.3 ; 6-21)$ & $6(6.9 ; 2-14)$ & $1(4.2 ; 0.1-21)$ & $0(-)$ \\
\hline Periapical radiolucency & $0(-)$ & $25(15.8 ; 10-22)$ & $9(11.1 ; 5-20)$ & $16(18.4 ; 10-28)$ & $2(8.3 ; 1-26)$ & $4(57.1 ; 18-90)$ \\
\hline
\end{tabular}

$\mathrm{N}=$ number of diagnosed events; $\%=$ estimated risk; $95 \% \mathrm{Cl}=95 \%$ confidence interval. 
in $15.8 \%$ (95\%CI 10-22) of the teeth with subluxation, and in $18.4 \%$ (95\%CI $10-28)$ of those with intrusive luxation.

\section{Discussion}

Half of the teeth examined had clinical sequelae, and about one third, radiographic sequelae; moreover, severe injuries had the highest occurrence of sequelae.

Children aged between 37 and 42 months presented a higher frequency of clinical sequelae, followed by children aged 25 to 36 months, whereas children aged between 43 and 60 months had a higher frequency of radiographic sequelae, followed by children aged 25 to 36 months. Another study, conducted with the same population found that the radicular maturity level of the primary teeth at the time of injury was associated with the sequelae presented. ${ }^{15}$ This is probably because the teeth of very young children are benefitted by better a vascular supply and greater resilience of the alveolar bone. Nevertheless, physiological resorption in older children can lead to gradual degeneration of the pulp tissue, and consequent vulnerability, even to slight injuries. ${ }^{6}$

Color change was a common clinical sequelae detected. Color can be yellowish in cases that indicate pulpal obliteration, or else darkened, suggesting necrotic pulp. However, a darkened tooth should be diagnosed as necrotic only when associated with abscess, swelling, and pathological periapical lesion resorption. ${ }^{16,17,18}$ Cardoso, and Rocha ${ }^{19}$ showed that among the teeth diagnosed with pulp necrosis and discoloration, $66.7 \%$ were grayish and $22.2 \%$ were yellowed. Discoloration is an important but not decisive factor in the diagnosis of pulp necrosis in traumatized primary teeth. When the traumatized tooth exhibits discoloration, the follow-up should have shorter intervals between appointments, especially during the first year after the trauma ${ }^{20}$. Furthermore, the approach of early intervention by endodontic treatment, when the root is radiographically intact in a tooth with dark discoloration, does not guarantee better long-term outcomes, compared with the non-interventionist approach. ${ }^{21}$

Teeth with crown-root fracture and avulsion presented higher frequency of premature loss.
Premature loss due to trauma can be the outcome of an avulsion, extraction after injury because of poor prognosis, ${ }^{22}$ late complications of the injury, or early exfoliation because of accelerated resorption of the root. ${ }^{20}$ The premature loss of primary incisors can affect aesthetics, quality of life, eating, speech development, arch integrity, development and eruption of the permanent successors, and development of oral habits. ${ }^{23}$

In the present study, premature loss was present in $79.3 \%$ of the cases of avulsion, since the teeth were replanted in 7 cases. It is worth mentioning that, as corroborated by other studies, dental trauma guides do not recommend the replantation of deciduous teeth, ${ }^{12,24,25}$ based on the risk of damaging the succeeding permanent tooth germen, because of the pressure exerted to push the coagulum against the follicle, or the risk of contaminating the alveolus, thus causing additional infections and/or inflammations. The lack of cooperation of a child during the treatment, and the risk of ankylosis, also constitute contraindications for the replantation of primary teeth. ${ }^{26}$ Moreover, a common consequence of replantation is pulp necrosis. Regarding inflammatory root resorption, it may be avoided or treated using endodontic procedures, that is, by removing the necrosis in the pulp tissue, which is the inflammatory reaction agent. ${ }^{27}$

Replantation was performed in the dental trauma center when conditions were favorable, such as little time elapsing from the time of injury to receiving first dental care, storage in a moist environment, collaborative behavior of the child and presence of adjacent teeth that enabled containment. The reasons for temporarily retaining the primary anterior teeth until the permanent teeth erupt are related to speech development, physiological aspects of chewing, and psychological effects on the child ${ }^{27}$. Successful results after this procedure have been demonstrated..$^{22,27,28}$ However, it should be noted that of the 7 replanted teeth, one had accelerated root resorption and 4 presented periapical radiolucency.

Periapical radiolucency was the most common radiographic sequela, connected to the fact that pulp necrosis is the most frequent post-traumatic consequence of deciduous teeth. ${ }^{29}$ More than half 
of the teeth with enamel-dentin-pulp fracture presented this sequela. A similar proportion was found previously, ${ }^{7}$ probably due to the risk of bacterial infection in the exposed area. In this study, even teeth with mild injuries presented a frequency of periapical radiolucency that was as high as teeth with severe injuries, especially those teeth with subluxation and enamel-dentine fracture. Injuries that promote the displacement of the tooth tend to exhibit necrosis, accompanied by periapical radiolucency, because of the irreversible traumas of the vascular supply and periodontal ligament. ${ }^{6,7,8,9,10,30}$ Necrotic pulp is an excellent growth culture for microorganisms, which may gain entry to the pulp after an additional injury, through a ruptured periodontal ligament (i.e. intrusive luxation), enamel-dentin cracks (i.e., enamel-dentin fracture, and more serious enamel, dentin and pulp fracture) or from the blood stream, by anachoresis. When the pulp becomes infected, invasion of bacterial products through the dentinal tubules sustains rapidly progressing inflammatory root resorption. ${ }^{17}$ Therefore, special care should be taken to obtain radiographs, perform the radiographic angulation correctly to allow as accurate as possible diagnosis, and conduct comparisons during follow-up. It is worth mentioning that no periapical radiolucency was present in the first exam of the child at the clinic. Thus, it is unlikely that the periapical radiolucency was really associated with other dental injuries that occurred before. However, some injuries admittedly go unnoticed by parents, ${ }^{31}$ and the children could have had other dental injuries during the clinical follow-up.

Avulsed teeth that were replanted and teeth with extrusive luxation, concussion or root fracture presented a $10 \%$ higher risk of accelerated root resorption. Accelerated resorption is not considered pathological, because no intervention is needed, but represents a disturbance in physiologic root resorption, as compared with homologous teeth. ${ }^{6}$

Teeth with subluxation, enamel fracture and lateral luxation presented a considerable risk of pulp obliteration. Obliteration may be the result of damage to the neurovascular supply. When revascularization is successful after the damage, it can induce pulp canal obliteration. ${ }^{12}$ In most cases teeth with obliteration do not present pulp complications. However, professionals must be aware that pulp necrosis may occur even in teeth with pulp obliteration. ${ }^{4}$

This study was conducted with data from a reference center, which allowed a large sample to be accompanied. A limitation is that some children were lost because they did not attend follow-up visits and because of low quality radiographs. An explanation is that radiographic examination may be difficulty to perform in very young children. However, this exam is of outmost importance in complementing the dental trauma visit, and cannot be underestimated, since many sequelae are diagnosed or confirmed only by a radiograph. ${ }^{12}$

The present study was the first to assess predicted risks of complications following dental trauma in the primary dentition. It was conducted in a dental trauma treatment center, following evidence-based treatment. The database included 774 teeth in 454 patients. Findings of the present study may help clinicians determine the risk of possible sequelae, considering the age of the children and the type of injury. This knowledge is important to determine the treatment plan and to better guide parents to recognize the importance of a long-term follow-up, regardless of injury severity.

\section{Conclusions}

The presence of clinical sequelae increased with injury severity, whereas the frequency of radiographic sequelae did not show association with degree of severity. The predicted risks of sequelae showed that hard tissue trauma tended to present color change, periapical radiolucency and premature loss as the most common sequelae, whereas color change, abnormal position, premature loss and periapical radiolucency were the most common sequelae for supporting tissue trauma.

\section{Acknowledgement}

Vanessa PP Costa received the support of CAPES (Brazilian Council for Improvement of Research) during the period that this study was performed. 


\section{References}

1. Jesus MA, Antunes LA, Risso PA, Freire MV, Maia LC. Epidemiologic survey of traumatic dental injuries in children seen at the Federal University of Rio de Janeiro, Brazil. Braz Oral Res. 2010;24(1):89-94. doi:10.1590/S1806-83242010000100015

2. Wendt FP, Torriani DD, Assunção MC, Romano AR, Bonow $\mathrm{ML}$, Costa CT et al. Traumatic dental injuries in primary dentition: epidemiological study among preschool children in South Brazil. Dent Traumatol. 2010;26(2):168-73. doi:10.1111/j.1600-9657.2009.00852.x

3. Viegas CM, Scarpelli AC, Carvalho AC, Ferreira FM, Pordeus IA, Paiva SM. Predisposing factors for traumatic dental injuries in Brazilian preschool children. Eur J Paediatr Dent. 2010;11(2):59-65.

4. Bhayya DP, Shyagali TR. Traumatic injuries in the primary teeth of 4- to 6-year-old school children in gulbarga city, India: a prevalence study. Oral Health Dent Manag. 2013;12(1):17-23.

5. Diab M, elBadrawy HE. Intrusion injuries of primary incisors. Part II: sequelae affecting the intruded primary incisors. Quintessence Int. 2000;31(5):335-41.

6. Borum MK, Andreasen JO. Sequelae of trauma to primary maxillary incisors. I. Complications in the primary dentition. Endod Dent Traumatol. 1998;14(1):31-44. doi:10.1111/j.1600-9657.1998.tb00806.x

7. Cardoso M, de Carvalho Rocha MJ. Traumatized primary teeth in children assisted at the Federal University of Santa Catarina, Brazil. Dent Traumatol. 2002;18(3):129-33. doi:10.1034/j.1600-9657.2002.00030.x

8. Amorim LF, Estrela C, Costa LR. Effects of traumatic dental injuries to primary teeth on permanent teeth: a clinical follow-up study. Dent Traumatol. 2011;27(2):117-21. doi:10.1111/j.1600-9657.2010.00959.x

9. Oikarinen K, Kassila O. Causes and types of traumatic tooth injuries treated in a public dental health clinic. Endod Dent Traumatol. 1987;3(4):172-7. doi:10.1111/j.1600-9657.1987.tb00620.x

10. Kenwood M, Seow WK. Sequelae of trauma to the primary dentition. J Pedod 1989;13(3):230-8.

11. International Association of Dental Traumatology - IADT. Dental trauma guide [homepage on the internet]. Copenhagen: International Association of Dental Traumatology; 2012 [cited 2012 Jan 08]. Available from: http://www.dentaltraumaguide.org

12. Flores MT, Malmgren B, Andersson L, Andreasen JO, Bakland LK, Barnett F, et al. Guidelines for the management of traumatic dental injuries. III. Primary teeth. Dent Traumatol. 2007;23(4):196-202. doi:10.1111/j.1600-9657.2007.00627.x

13. Andreasen JO, Andreasen FM, Andersson L. Textbook and color atlas of traumatic injuries to the teeth. 4 nd ed. Oxford: Blackwell Munskgaard; 2007.
14. Bijella MFTB YF, Lopes ES. Causas e sequelas de traumatismos em incisivos decíduos de crianças brasileiras, de Bauru, Estado de São Paulo. Rev Paul Odontol. 1987;9:38-47.

15. Qassem A, Goettems M, Torriani DD, Pappen FG. Radicular maturity level of primary teeth and its association with trauma sequelae. Dent Traumatol. 2014;30(3):227-31. doi:10.1111/edt.12072

16. Cardoso M, Rocha MJ. Federal University of Santa Catarina follow-up management routine for traumatized primary teeth - part 1. Dent Traumatol. 2004;20(6):307-13. doi:10.1111/j.1600-9657.2004.00260.x

17. Holan G. Development of clinical and radiographic signs associated with dark discolored primary incisors following traumatic injuries: a prospective controlled study. Dent Traumatol. 2004;20(5):276-87. doi:10.1111/j.1600-9657.2004.00285.x

18. Malmgren B, Andreasen JO, Flores MT, Robertson A, DiAngelis AJ, Andersson L et al. International Association of Dental Traumatology guidelines for the management of traumatic dental injuries: 3. Injuries in the primary dentition. Dent Traumatol. 2012;28(3):174-82. doi:10.1111/j.1600-9657.2012.01146.x

19. Cardoso M, Rocha MJC. Association of crown discoloration and pulp status in traumatized primary teeth. Dent Traumatol. 2010;26(5):413-6. doi:10.1111/j.1600-9657.2010.00919.x

20. Cardoso M, Rocha MJC. Identification of factors associated with pathological root resorption in traumatized primary teeth. Dent Traumatol. 2008;24(3):343-9. doi:10.1111/j.1600-9657.2007.00554.x

21. Holan G. Long-term effect of different treatment modalities for traumatized primary incisors presenting dark coronal discoloration with no other signs of injury. Dent Traumatol. 2006;22(1):14-7. doi:10.1111/j.1600-9657.2006.00346.x

22. Arikan V, Sari S, Sonmez H. The prevalence and treatment outcomes of primary tooth injuries. Eur J Dent. 2010;4(4):447-53.

23. Holan G, Needleman HL. Premature loss of primary anterior teeth due to trauma - potential short- and long-term sequelae. Dent Traumatol. 2014;30(2):100-6. doi:10.1111/edt.12081

24. Wilson CF. DIY guide to primary tooth trauma repair. Tex Dent J. 1997;114(1):43-7.

25. Spinosa GM. Traumatic injuries to the primary and young permanent dentitions. Univ Tor Dent J. 1990;3(2):34-6.

26. Flores MT, Andreasen JO, Bakland LK, Feiglin B, Gutmann JL, Oikarinen K et al. Guidelines for the evaluation and management of traumatic dental injuries. Dent Traumatol. 2001;17(5):193-8. doi:10.1034/j.1600-9657.2001.170501.x 
27. Rocha MJC, Cardoso M. Reimplantation of primary tooth--case report. Dent Traumatol. 2008;24(4):e4-10. doi:10.1111/j.1600-9657.2008.00557.x

28. Filippi A, Pohl Y, Kirschner H. Replantation of avulsed primary anterior teeth: treatment and limitations. ASDC J Dent Child. 1997;64(4):272-5.

29. Altun C, Cehreli ZC, Güven G, Acikel C. Traumatic intrusion of primary teeth and its effects on the permanent successors: a clinical follow-up study. Oral Surg Oral Med Oral Pathol Oral Radiol Endod. 2009;107(4):493-8. doi:10.1016/j.tripleo.2008.10.016
30. Costa VP, Bertoldi AD, Baldissera EZ, Goettems ML, Correa MB, Torriani DD. Traumatic dental injuries in primary teeth: severity and related factors observed at a specialist treatment centre in Brazil. Eur Arch Paediatr Dent. 2014;15(2):83-8. doi:10.1007/s40368-013-0068-x

31. Costa VP, Amaral CC, Goettems ML, Pinheiro RT, Demarco FF. Maternal perception of the occurrence of traumatic dental injuries in children: a cohort study of south Brazil. Int Dent J. 2016. doi:10.1111/idj.12215 